\title{
What to do when an actively bleeding, adult, legally competent Jehovah's Witness proposed for an urgent surgery consciously refuses a blood transfusion? The Portuguese perspective.
}

\author{
Alves, DR ${ }^{1}$; Antunes, $\mathrm{C}^{1}$; Martins, $\mathrm{D}^{1}$; Ribeiro, $\mathrm{P}^{2}$ ( ${ }^{1}$ Anaesthesiology resident; ${ }^{2}$ Anaesthesiology Fellow) \\ Centro Hospitalar de Lisboa Ocidental, Lisbon, Portugal; Head of Department: Manuel Chedas
}

Introduction: Jehovah's Witnesses (JW) first appeared as an independent cult in the $19^{\text {th }}$ century (circa 1870's) in the USA, and have since reached 239 countries, presently accounting for more than 8,2 million believers ${ }^{1}$. JW patients ordinarily refuse blood products, which leads to important constraints in perioperative management when a blood transfusion is deemed lifesaving. Different bioethical and legal principles collide in such cases, of which anaesthesiologists caring for these patients should be aware.

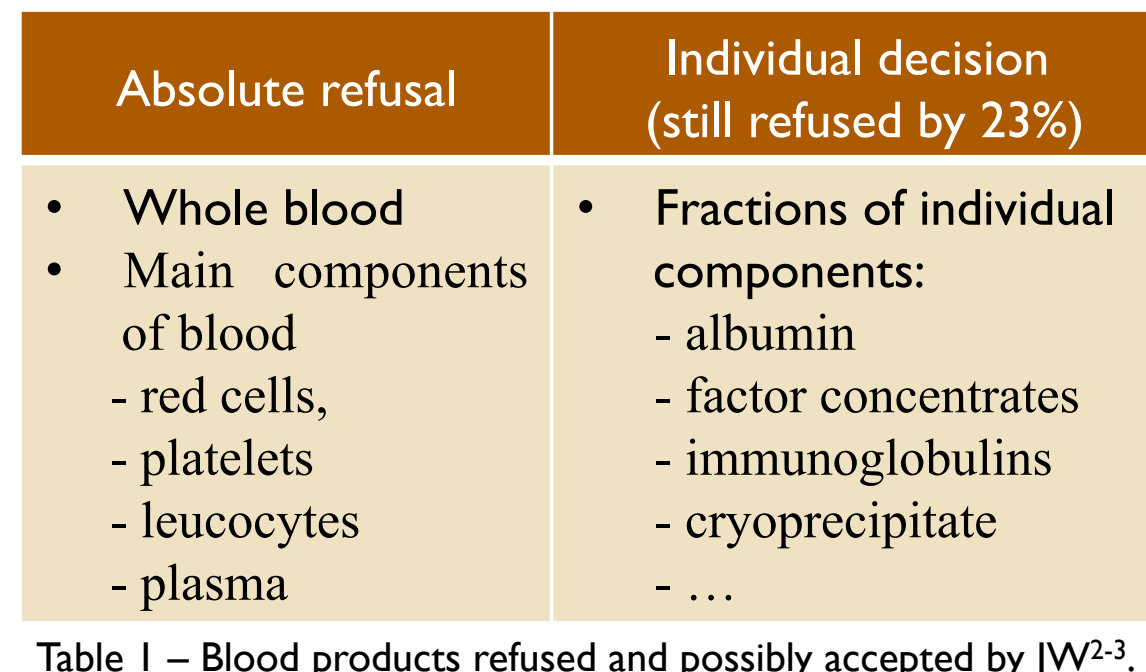

Case report:

Female, 65-year-old patient submitted to right hemicolectomy for a malignant tumour in the ileocecal appendix. 1 hour after arrival at the postanaesthetic care unit she was hypotensive, oliguric, with ill-perfused extremities (capillary refill time 4 seconds), and active bleeding as evidenced by a haematic drainage of $400 \mathrm{cc}$. The patient was still neurologically intact, and still refused a blood transfusion, keeping with her previously expressed living will determinations. The decision was made to reintervene, but abstention from using blood products clearly threatened the vital prognosis of the patient.

Consent:
- Conscious, cooperative,
coherent speech;
Signed a valid "Living
Will", specifying that
blood products should
not be used
Still refuses
administration of blood
products, clearly
understanding the
consequences

Cold extremities, with diuresis $<0,5 \mathrm{~mL} / \mathrm{Kg} / \mathrm{h}$ Active drainage of haematic content from the abdominal drain $1000 \mathrm{~mL}$ consequences

\section{Discussion: The 4 fundamental principles of Bioethics and Portuguese Law}

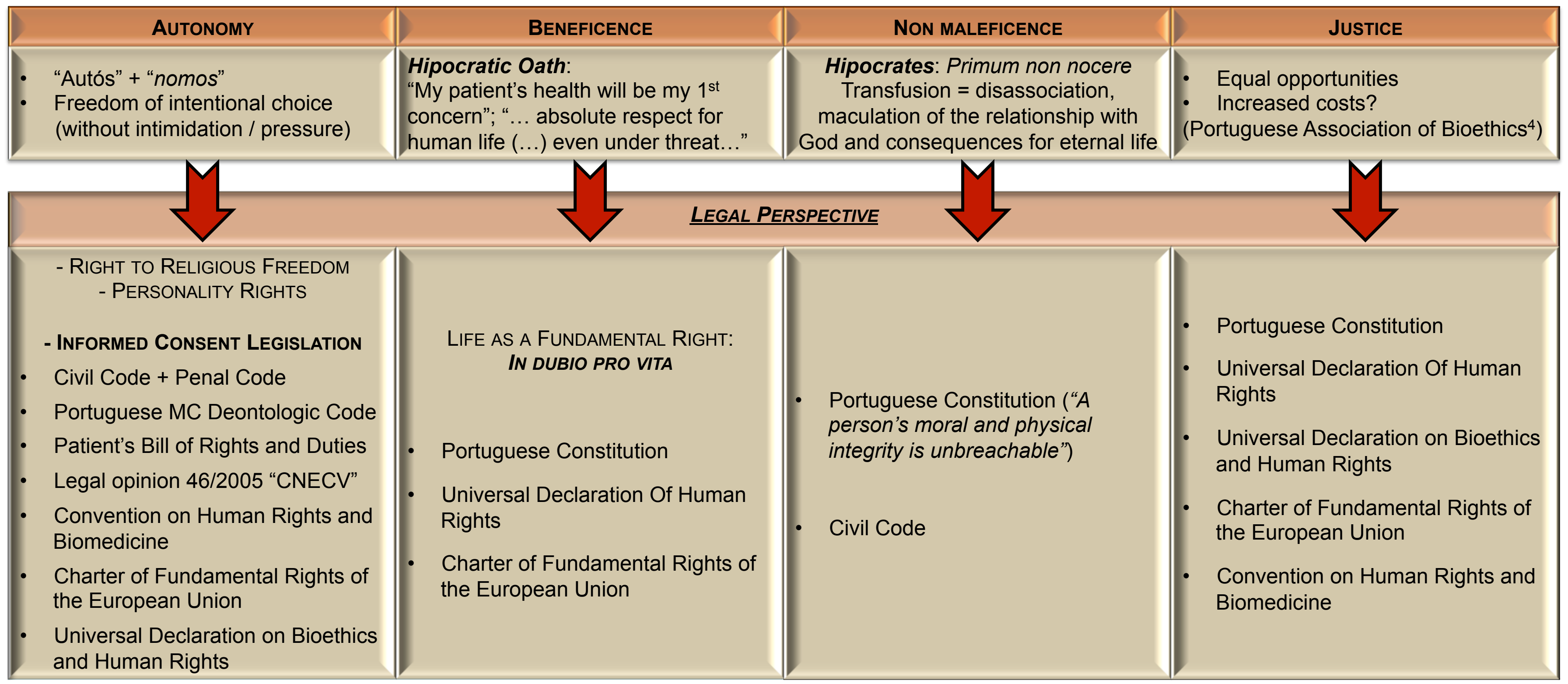

\section{Result:}

- Collision of ideas between patient and physician

- Collision of fundamental Bioethical principles

- Collision of fundamental legal principles

Status quo:

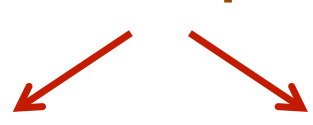

- Valid Living Will

- Free, informed decision (patient-doctor relationship)

Respect for autonomy
- Non-valid Living Will/ informed consent

- "Change of heart"

- Cohersion Judicial clarification (in dubio pro vita)

\begin{tabular}{|c|c|}
\hline LIVING WILL LEGISLATION & CONSCIOUS OBJECTION \\
\hline $\begin{array}{l}\text { - Law } 25 / 2012 \\
\text { - } \\
\text { - } \\
\text { - } \text { yeart years valididity } \\
\text { clear instication, time, date, place, } \\
\text { - Health proxy }\end{array}$ & $\begin{array}{l}\text { - Art } 37^{\text {th }}+41^{\text {th }}+49^{\text {th }} \\
\text { Portuguese Medical } \\
\text { Regulatory Body's } \\
\text { Deontologic Code } \\
\text { Law } 25 / 2012\end{array}$ \\
\hline
\end{tabular}

\section{References:}

1. WatchTower Society JW. JW.org. http://wwwjworg/pt/ (Cons. 30/12/2015)

2. WatchTower Society JW. Appendix: Blood fractions and surgical procedures. http://wol.jw.org/en/wol/d/r1//p-e/1102008086. (Cons. 31/10/2015) 3 . Elder L. Why some Jehova's Witnesses accept blood and conscientiously reject official Watchtower Society blood policy. J Med Ethics. 2000;26:375-380. 4. Melo H, Nunes R. Parecer $n^{\circ}$ P/05/APB/06 sobre Directivas Antecipadas de Vontade. Associação Portuguesa de Bioética. 20061-25

5. Portuguese legislation identified throughout the text 